\title{
TENSILE PROPERTIES OF A FLEXIBLE POLYMER-CEMENT COMPOSITE CONTAINING PORTLAND CEMENT AND VAE EMULSION
}

\author{
\#ER-LEI BAI*, GAO-JIE LIU*, JIN-YU XU*, **, NING YANG***, CHEN-HAO WEN* \\ *Teaching and Research Office of Airport Construction Engineering, Air Force Engineering University, Xi'an 710038, China \\ **College of Mechanics and Civil Architecture, Northwest Polytechnic University, Xi'an 710072, China \\ ***The PLA Unit 75840, Guangzhou 510665, China \\ "E-mail: bwxkgy@163.com
}

Submitted August 4, 2019; accepted September 27, 2019

\begin{abstract}
Keywords: Polymer-cement composite, VAE emulsion, Tensile properties, Orthogonal experiment design
The aim of this paper is to investigate the tensile properties of a flexible polymer-cement composite (FPCC) which was mainly prepared by vinyl acetate-ethylene copolymer emulsion and Portland cement. An orthogonal experiment design was used to investigate the effects of the powder-emulsion ratio, the cement ratio and the filler type on the basic tensile indicators including the elastic recovery ratio, the tensile strength, the critical tensile strain, the tensile modulus and the elongation at the break. The results indicate that the major influence factors for the tensile properties of the FPCC are the powder-emulsion ratio and the cement ratio. With an increase in these two parameters, the tensile strength and the tensile modulus increase and the elastic recovery ratio, the critical tensile strain and the elongation at the break decrease. Furthermore, for the tensile strength and the tensile modulus, the influence of the cement ratio is more significant than the powder-emulsion ratio, and this is reversed for the case of the elastic recovery ratio, the critical tensile strain and the elongation at the break. The effect of the filler type on the FPCC is far less than the other two factors although its $F$ test results are significant. An FPCC added with ground calcium carbonate exhibits a relatively higher tensile strength and tensile modulus. An FPCC added with a quartz powder has a better deformation ability.
\end{abstract}

\section{INTRODUCTION}

A polymer-cement composite is a high performance organic-inorganic composite which is mainly formed by cement hydration and polymer film formation $[1,2]$. The major materials used for a polymer-cement composite include polymers, cement, water, fillers, aggregates and other additives. A polymer-cement composite not only has the many merits of a cementitious material, such as good durability, better cost performance and low environment pollution, but it also has excellent capacities in flexibility, deformability and adhesion properties [3-9].

Based on the contents of the polymer components, the polymer-cement composite can be classified as two types: a rigid polymer-cement composite (RPCC) with lower contents of polymer components and a flexible polymer-cement composite (FPCC) with higher contents of polymer components. The major binder material in the RPCC is still the cement component and the polymer to cement ratio is usually less than $30 \%$. The polymer components in the RPCC just act as a modifier to improve the cementitiousness and to fill up or bridge the internal flaws of the material. Thus, the RPCC ma- terials are also called a polymer modified mortar or a polymer modified concrete. Compared with ordinary cementitious materials, the RPCC has better durability, cementitiousness and toughness, which is mainly used as a functional mortar (or a concrete) or a building adhesive [10-15].

In the FPCC, the polymer component is not just used as a modifier, but acts as the primary binder material. With an increase in the polymer fraction, the inorganic components and the voids inside the material are wrapped and filled by the polymer film, which obviously improves the tensile and adhesive performances of the material. The FPCC materials are mainly used as a waterproofing coating and a sealant material [16-21].

This paper mainly aims to explore the tensile performances of the FPCC material using a vinyl acetate-ethylene copolymer emulsion (VAE emulsion) and Portland cement as the major raw materials. The orthogonal experiment design was used to investigate the effects of the powder-emulsion ratio, the cement ratio and the filler type on the basic tensile indicators including the elastic recovery ratio, the tensile strength, the critical tensile strain, the tensile modulus and the elongation at the break. 


\section{EXPERIMENTAL}

Materials and specimen preparation

The materials used to prepare the FPCC specimens involve binding materials, inorganic fillers and an admixture. The binding materials include a commercially available VAE emulsion (Solid content: $55 \pm 1 \%$; Brookfield viscosity: $1500 \sim 5000 \mathrm{mPa} \cdot \mathrm{s} ; \mathrm{pH}: 4.5 \sim 6.0$; Average particle size: $1.5 \mu \mathrm{m} ; T_{g}:-10{ }^{\circ} \mathrm{C}$; MFT: $0{ }^{\circ} \mathrm{C}$ ) and ordinary Portland cement which is classified as 42.5R according to the Chinese standard (GB 175-2007/ XG1-2009) [22]. In the preparation of the sample, water in the VAE emulsion hydrated the cement. The inorganic fillers include talc powder (600 mesh, $\mathrm{SiO}_{2}$ content: $60 \%, \mathrm{MgO}$ content: $30 \%$ ), quartz powder (300 mesh, $\mathrm{SiO}_{2}$ content: $>99 \%$ ) and ground calcium carbonate (500 mesh, purity: > $99 \%$ ). The admixture includes a polycarboxylate type dispersant, a dodecanol ester type film coalescing aid and a metal soap type defoamer. The technical performance of each admixture is listed in Table 1.

The preparation procedure for the FPCC specimens used for the tensile test were as follows:

- The dispersant, film coalescing aid and half of the defoamer were added into the emulsion and mixed for $150 \mathrm{~s}$ by using an electric mixer with a stirring rate of $300 \mathrm{r} \cdot \mathrm{min}^{-1}$.

- All the pre-mixed powder materials were added into the emulsion and mixed for $10 \mathrm{~min}$ with a stirring rate of $700 \mathrm{r} \cdot \mathrm{min}^{-1}$.
- The other half of the defoamer was added and the mixture was mixed for $3 \mathrm{~min}$ with a stirring rate of $120 \mathrm{r} \cdot \mathrm{min}^{-1}$.

- The mixture was hand mixed for $10 \mathrm{~min}$ by using a glass rod in order to further remove the air entrained.

- The mixture was cast into a hollow volume $(50 \times 12 \times$ $\times 12 \mathrm{~mm}$ ) formed by mortar substrates and blocks. The dimensions of the substrate and block follows the Chinese standard (GB/T 13477-2002) [23].

- The blocks were removed after 4 days of curing in a room (with a temperature of $20 \pm 2{ }^{\circ} \mathrm{C}$ ), and then the specimens were cured for additional 24 days.

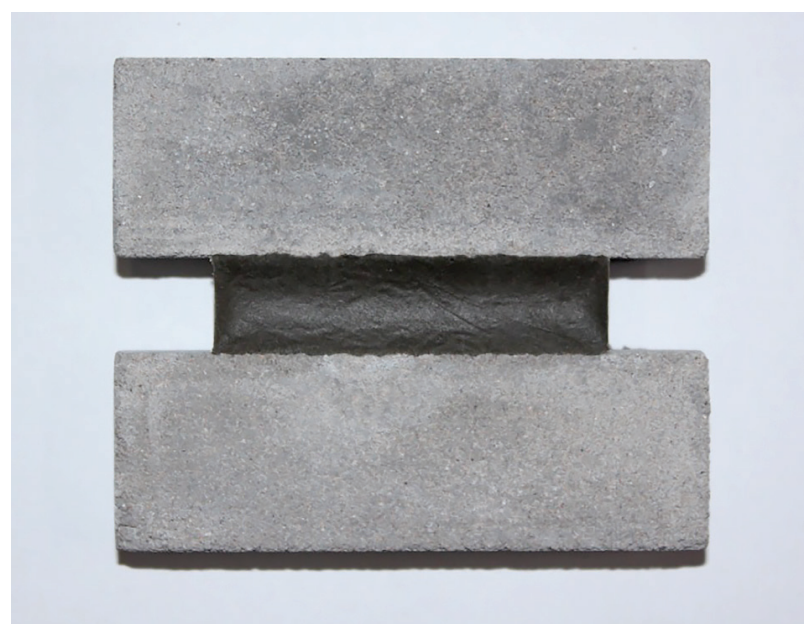

Figure 1. The FPCC specimen.

Table 1. The technical performance of the admixture.

\begin{tabular}{|c|c|c|}
\hline Type of admixture & Parameters & Value \\
\hline \multirow{8}{*}{$\begin{array}{l}\text { Polycarboxylate } \\
\text { type dispersant }\end{array}$} & Main ingredients & Polycarboxylate sodium salt \\
\hline & Appearance & Pale yellow liquid \\
\hline & Solid content & $42.5 \%$ \\
\hline & $\mathrm{pH}$ & 7.5 \\
\hline & Brookfield viscosity $\left(25^{\circ} \mathrm{C}\right)$ & $450 \mathrm{mPa} \cdot \mathrm{s}$ \\
\hline & Specific gravity $\left(25^{\circ} \mathrm{C}\right)$ & 1.29 \\
\hline & Ionic property & Anion \\
\hline & Solubility & Soluble in water \\
\hline \multirow{6}{*}{$\begin{array}{l}\text { Dodecanol ester } \\
\text { type film } \\
\text { coalescing aid }\end{array}$} & Main ingredients & Dodecyl alcohol ester \\
\hline & Appearance & Colourless transparent liquid \\
\hline & Molecular formula & $\mathrm{C} 1_{2} \mathrm{H}_{2} \mathrm{O}_{3}$ \\
\hline & Content & $\geq 99 \%$ \\
\hline & Moisture content & $\leq 0.1 \%$ \\
\hline & Acidity & $\leq 0.05 \%$ \\
\hline \multirow{7}{*}{$\begin{array}{l}\text { Metal soap type } \\
\text { defoamer }\end{array}$} & Appearance & Yellowish brown turbid liquid \\
\hline & Specific gravity $\left(20^{\circ} \mathrm{C}\right)$ & 0.89 \\
\hline & Ionic property & Non-Ionic \\
\hline & Dispersibility & Dispersed in water \\
\hline & Brookfield viscosity $\left(25^{\circ} \mathrm{C}\right)$ & $170 \mathrm{mPa} \cdot \mathrm{s}$ \\
\hline & $\mathrm{pH}$ & 5.1 \\
\hline & Features & $\begin{array}{l}\text { Widely used in all kinds of } \\
\text { aqueous polymer emulsion }\end{array}$ \\
\hline
\end{tabular}




\section{Orthogonal experiment design}

The preparation of the FPCC involves several material types and formulation parameters, which is a typical multifactor-multilevel problem. Considering the full factorial experiment is difficult and expensive to carry out, an orthogonal experiment design method was used in this study [24]. Based on the orthogonal array $L_{9}\left(3^{4}\right)$, the following three influence factors are analysed, including the powder-emulsion ratio (i.e., the ratio of the cement and filler mass to the emulsion mass), the cement ratio (i.e., the ratio of the cement mass to the total mass of the cement and the filler), and the filler type. The additional factor is included as an error array. For each influence factor, three levels are selected as tabulated in Table 2. Tables 3 and 4 list the orthogonal experiment scheme and the formulation for each dozen samples (the numerical code in parentheses, as shown in Table 2, represents the corresponding level number). The mass fraction of each assisted additive follows the recommended value given by the producer. Specifically,

Table 2. The influence factors and the level values.

\begin{tabular}{lccc}
\hline Level & Factor A & Factor B & \begin{tabular}{c} 
Factor C \\
\cline { 2 - 4 }
\end{tabular} \\
\hline sowder-emul- & $\begin{array}{c}\text { Cement } \\
\text { ratio }\end{array}$ & $\begin{array}{c}\text { Filler } \\
\text { type }\end{array}$ \\
\hline Level 1 & 0.85 & $10 \%$ & talc powder \\
\hline Level 2 & 0.65 & $35 \%$ & $\begin{array}{c}\text { ground calcium } \\
\text { carbonate }\end{array}$ \\
\hline Level 3 & 0.45 & $60 \%$ & quartz powder \\
\hline
\end{tabular}

the proportions of defoamer and dispersant are $0.3 \%$ and $0.7 \%$ of the total mass of the emulsion and the powder materials, respectively; the proportion of the film coalescing aid is $5 \%$ of the emulsion mass.

The elastic recovery ratio, the tensile strength, the tensile modulus, the critical tensile strain and the elongation at the break are investigated. An analysis of range (ANORA) and an analysis of variance (ANOVA) were performed to analyse the obtained data. In the ANORA, $k_{j}$ represents the average value of the experimental

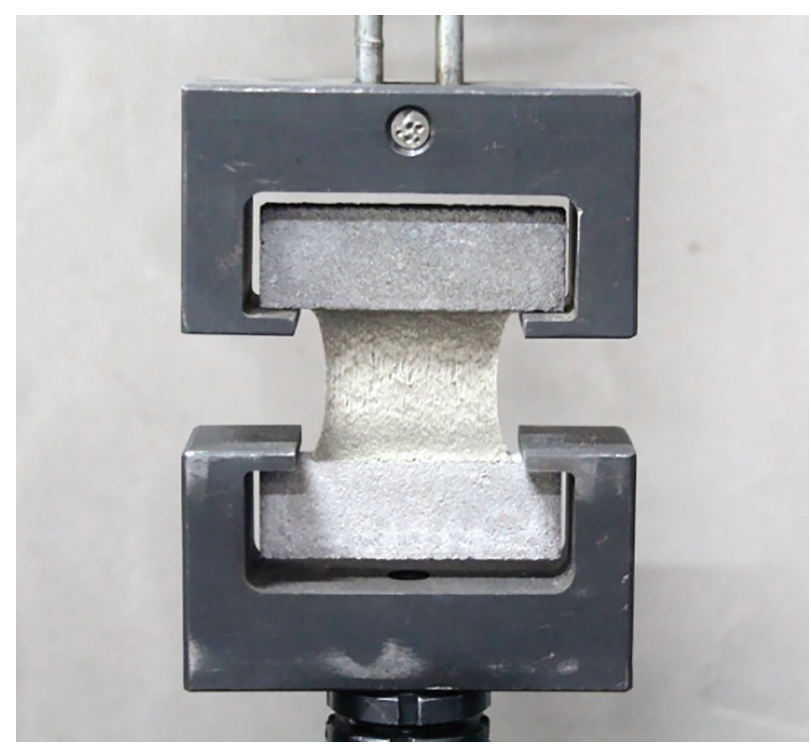

Figure 2. The tensile test.

Table 3. The influence factors and the level values.

\begin{tabular}{ccccc}
\hline $\begin{array}{c}\text { Experiment } \\
\text { number }\end{array}$ & $\begin{array}{c}\text { Factor A } \\
\text { Powder-emulsion ratio }\end{array}$ & $\begin{array}{c}\text { Factor B } \\
\text { Cement ratio }\end{array}$ & $\begin{array}{c}\text { Factor C } \\
\text { Filler type }\end{array}$ & Error \\
\hline G1 & $0.85(1)$ & $10 \%(1)$ & talc powder (1) & $(1)$ \\
G2 & $0.85(1)$ & $35 \%(2)$ & ground calcium carbonate (2) & $(2)$ \\
G3 & $0.85(1)$ & $60 \%(3)$ & quartz powder (3) & $(3)$ \\
G4 & $0.65(2)$ & $10 \%(1)$ & quartz powder (3) & $(2)$ \\
G5 & $0.65(2)$ & $35 \%(2)$ & talc powder (1) & $(3)$ \\
G6 & $0.65(2)$ & $60 \%(3)$ & ground calcium carbonate (2) & $(1)$ \\
G7 & $0.45(3)$ & $10 \%(1)$ & ground calcium carbonate (2) & $(3)$ \\
G8 & $0.45(3)$ & $35 \%(2)$ & quartz powder (3) & $(1)$ \\
G9 & $0.45(3)$ & $60 \%(3)$ & talc powder (1) & $(2)$ \\
\hline
\end{tabular}

Table 4. The formulation for each dozen samples.

\begin{tabular}{|c|c|c|c|c|c|c|c|}
\hline $\begin{array}{l}\text { Experiment } \\
\text { number }\end{array}$ & Unit & $\begin{array}{c}\text { VAE } \\
\text { emulsion }\end{array}$ & Filler & Cement & Defoamer & Dispersant & $\begin{array}{l}\text { Film coales- } \\
\text { cing aid }\end{array}$ \\
\hline G1 & (g) & 89.2 & 68.2 & 7.6 & 0.5 & 1.2 & 4.5 \\
\hline G2 & (g) & 89.2 & 49.3 & 26.5 & 0.5 & 1.2 & 4.5 \\
\hline G3 & (g) & 89.2 & 30.3 & 45.5 & 0.5 & 1.2 & 4.5 \\
\hline G4 & (g) & 89.2 & 52.2 & 5.8 & 0.4 & 1.0 & 4.5 \\
\hline G5 & (g) & 89.2 & 37.7 & 20.2 & 0.4 & 1.0 & 4.5 \\
\hline G6 & (g) & 89.2 & 23.2 & 34.8 & 0.4 & 1.0 & 4.5 \\
\hline G7 & (g) & 89.2 & 36.1 & 4.0 & 0.4 & 0.9 & 4.5 \\
\hline G8 & (g) & 89.2 & 26.1 & 14.0 & 0.4 & 0.9 & 4.5 \\
\hline G9 & (g) & 89.2 & 16.1 & 24.1 & 0.4 & 0.9 & 4.5 \\
\hline
\end{tabular}


results when the level of each factor is $j(j=1,2,3)$. $R$ is defined as the range between the maximum and minimum value of $k_{j}$. A large $R$ means the greater importance of the factor. In the ANOVA, the statistical variable $F_{i}$ (shown in Equation 1) is used to indicate the significance of the factor $i$. If $F_{i}$ ranks higher than the $F$ standard value ( $F_{0.01}$ in this study), it means that factor $i$ has significant effects on the experiment indicator and it is marked with the symbol *. Additionally, in order to further quantify the influence of each factor on the variation of the experiment indicator, a contribution ratio $(\rho)$ is defined and can be calculated by Equations 2 and 3 [24]. The larger the $\rho$ value is, the greater the influence is.

$$
\begin{gathered}
F_{i}=\left(S_{i}^{2} / f_{i}\right) /\left(S_{e}^{2} / f_{e}\right) \\
\rho_{i}=\frac{S_{i}-f_{i}\left(S_{e}^{2} / f_{e}\right)}{S_{\mathrm{T}}^{2}} \times 100 \% \\
\rho_{e}=f_{\mathrm{T}} \frac{S_{e}^{2}}{f_{e}} \times 100 \%
\end{gathered}
$$

where $S^{2}$ represents the sum of the squares of the deviations; $f$ represents the degree of freedom; the subscripts $i$, $e$ and $\mathrm{T}$ represent the factor $i(i=\mathrm{A}, \mathrm{B}, \mathrm{C})$, the error and the total influence factors, respectively.

\section{Test method}

The tensile test at the maintained extension was conducted by a self-made apparatus. The specimen was firstly extended with a pre-set width $(60 \%$ of its original width). Then the position blocks were set and the specimen was kept in the extension state for 1 day. After that, the position blocks were removed and the specimen was horizontally laid on the table for 1 day. Lastly, the specimen width, after the elastic recovery, was measured and the elastic recovery ratio $\left(R_{\mathrm{e}}\right)$ can be calculated by Equation 4. Where $W_{0}, W_{1}$ and $W_{2}$ are the original width, the width after the extension and the width after the elastic recovery for the specimen, respectively. All the tests were performed on 3 replicates.

$$
R_{e}=\frac{W_{1}-W_{2}}{W_{1}-W_{0}} \times 100 \%
$$

The tensile test of the specimen was conducted by an electronic tensile testing machine with a loading rate of $5 \mathrm{~mm} \cdot \mathrm{min}^{-1}$ (shown in Figure 2). Three tests were repeated for each group and the corresponding load-displacement curves were recorded.

\section{RESULTS AND DISCUSSION}
Analysis of the tensile properties at the maintained extension and elastic recovery ratio

Figure 3 shows the typical forms of the FPCC specimens at the maintained extension. It can be seen that the adhesion failure occurred at the adhesion surface between the mortar substrates and the FPCC in group G3 (marked out in a red box in Figure 3), the other groups have no failures. The adhesion failure that occurred in the G3 group is mainly attributed to its higher powder material ratio and cement ratio, which enhance the cohesion strength and decrease the flexibility of the specimen. As a result, the applied loading only can be consumed by way of the adhesion failure.

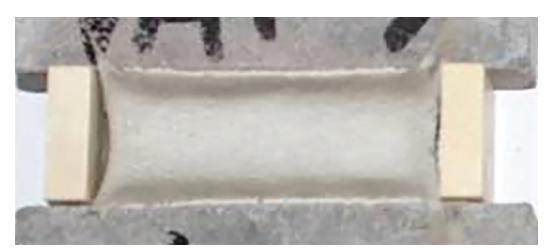

G1

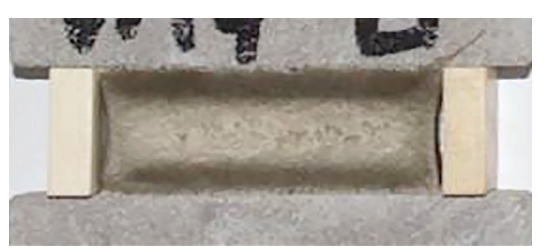

G4

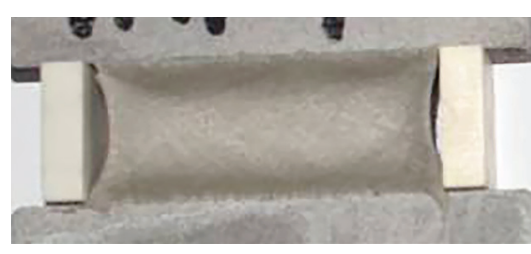

G7

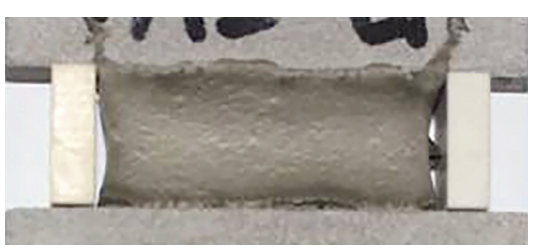

G2

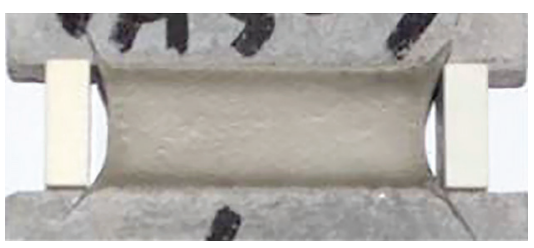

G5

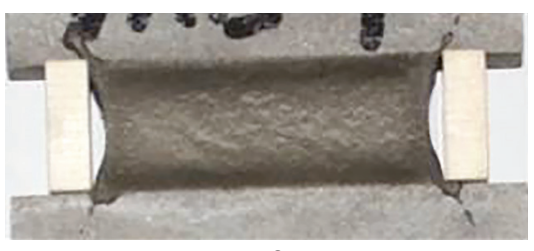

G8

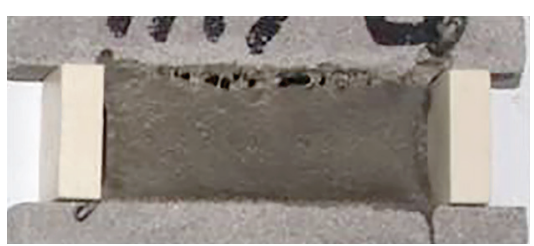

G3

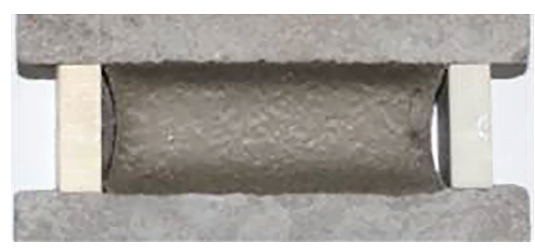

G6

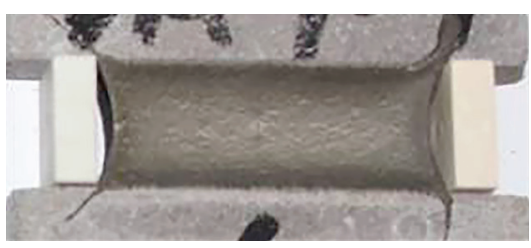

G9

Figure 3. The typical forms of the FPCC specimens under the tensile test at the maintained extension

Ceramics - Silikáty 64 (1) 92-99 (2020) 
Figure 4 shows the test data of the elastic recovery ratio. The corresponding ANORA and ANOVA results are listed in Table 5. It can be seen that a decrease in the powder-emulsion ratio and cement ratio lead to an increase in the elastic recovery ratio. The specimens added with quartz powder have a better elastic recovery ability than those added with the other two fillers. The influential orders of the three factors to the elastic recovery ratio is the powder-emulsion ratio $>$ the cement ratio $>$ the filler type. The variation of the elastic recovery ratio is mainly contributed by the powder-emulsion ratio and the cement ratio, since their contribution ratios nearly amount to $90 \%$. In addition, the contribution ratio of the filler type is close to that of the error. Thus, the effect of the filler type is very limited although its $F$ value is greater than the $F$ standard value.

\section{Analysis of the tensile strength}

The peak stress during the loading process is adopted as the tensile strength of the specimen. The test data of the tensile strength are presented in Figure 5. Table 5 summarises its ANORA and ANOVA results. From Figure 5 and Table 6 , it can be found that the tensile strength

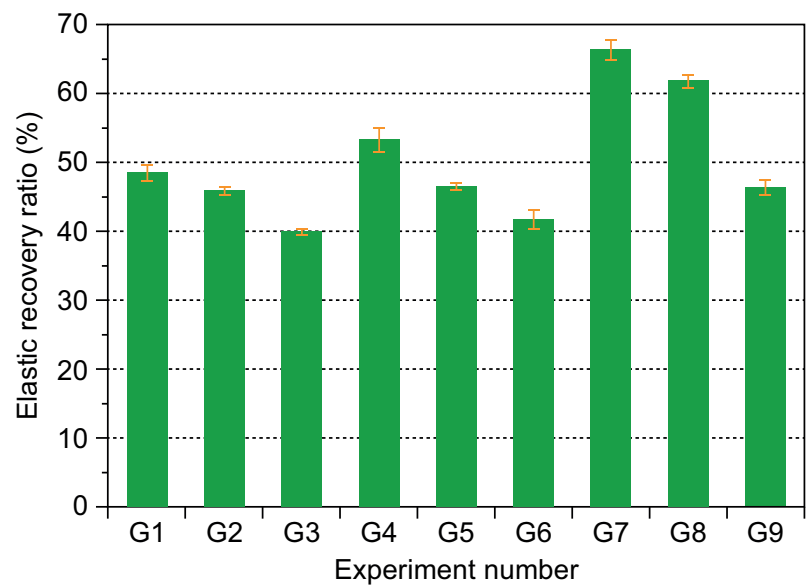

Figure 4. The test results of the elastic recovery ratio. increases with an increase in the powder-emulsion ratio and the cement ratio. When added with the ground calcium carbonate, the specimen shows a higher tensile strength. The influential orders of the three factors to the tensile strength is the cement ratio $>$ the powderemulsion ratio $>$ the filler type. Besides, based on the $F$ value, all of these three factors show a significant effect. However, the contribution ratio of the filler type is much less than the other two factors. Thus, the tensile strength is actually not sensitive to the filler type.

\section{Analysis of the critical tensile strain}

The critical tensile strain of the specimen is the strain level corresponding to the tensile strength. Figure 6 and Table 6 present the test data, the ANORA and ANOVA results of the critical tensile strain. As can be seen from Figure 6 and Table 7, the critical tensile strain increases with a decrease in the powder-emulsion ratio and the cement ratio. Especially when the powder-emulsion ratio decreases to 0.45 and the cement ratio decreases to below $35 \%$, the increase in the critical tensile strain is pronounced. While the specimen has a larger powderemulsion ratio $(0.85)$, particularly a larger cement ratio

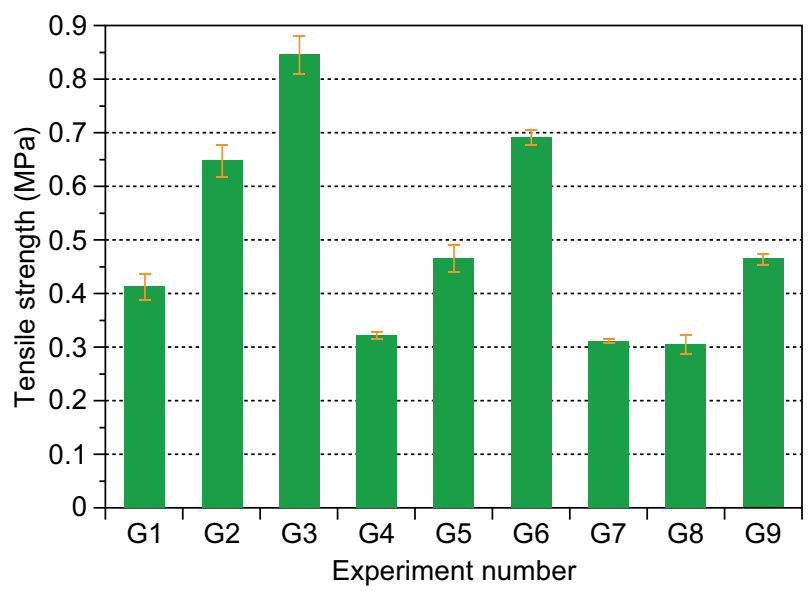

Figure 5. The test results of the elastic recovery ratio.

Table 5. The ANORA and ANOVA results of the elastic recovery ratio.

\begin{tabular}{|c|c|c|c|c|c|c|c|c|c|c|}
\hline \multirow{2}{*}{ Influence factor } & \multicolumn{5}{|c|}{ ANORA } & \multicolumn{5}{|c|}{ ANOVA } \\
\hline & $k_{1}$ & $k_{2}$ & $k_{3}$ & $R$ & $S^{2}$ & $F$ & $F$ value & $F_{0.01}$ & $\rho$ & Significance \\
\hline Powder-emulsion ratio & 44.7 & 47.1 & 58.1 & 13.4 & 0.092 & 2 & 124.47 & 5.85 & $47.2 \%$ & $*$ \\
\hline Cement ratio & 56.0 & 51.3 & 42.7 & 13.3 & 0.082 & 2 & 111.98 & 5.85 & $42.5 \%$ & $*$ \\
\hline Filler type & 47.1 & 51.3 & 51.6 & 4.4 & 0.011 & 2 & 14.93 & 5.85 & $5.3 \%$ & $*$ \\
\hline Error & l & / & / & / & 0.007 & 20 & I & 5.85 & $5.0 \%$ & / \\
\hline
\end{tabular}

Table 6. The ANORA and ANOVA results of the tensile strength.

\begin{tabular}{|c|c|c|c|c|c|c|c|c|c|c|}
\hline \multirow{2}{*}{ Influence factor } & \multicolumn{5}{|c|}{ ANORA } & \multicolumn{5}{|c|}{ ANOVA } \\
\hline & $k_{1}$ & $k_{2}$ & $k_{3}$ & $R$ & $S^{2}$ & $f$ & $F$ value & $F_{0.01}$ & $\rho$ & Significance \\
\hline Powder-emulsion ratio & 0.635 & 0.493 & 0.360 & 0.275 & 0.340 & 2 & 79.74 & 5.85 & $37.5 \%$ & $*$ \\
\hline Cement ratio & 0.348 & 0.472 & 0.667 & 0.319 & 0.464 & 2 & 109.05 & 5.85 & $51.4 \%$ & $*$ \\
\hline Filler type & 0.447 & 0.550 & 0.490 & 0.103 & 0.048 & 2 & 11.25 & 5.85 & $4.9 \%$ & $*$ \\
\hline Error & 1 & l & 1 & I & 0.043 & 20 & / & 5.85 & $6.2 \%$ & l \\
\hline
\end{tabular}


(60\%), the critical tensile strain drops sharply. The influential orders of the three factors to the critical tensile strain is the powder-emulsion ratio $>$ the cement ratio $>$ the filler type. Although the specimens added with quartz powder show a larger critical tensile strain, the effect of the filler type is still far less pronounced due to its lower contribution ratio.

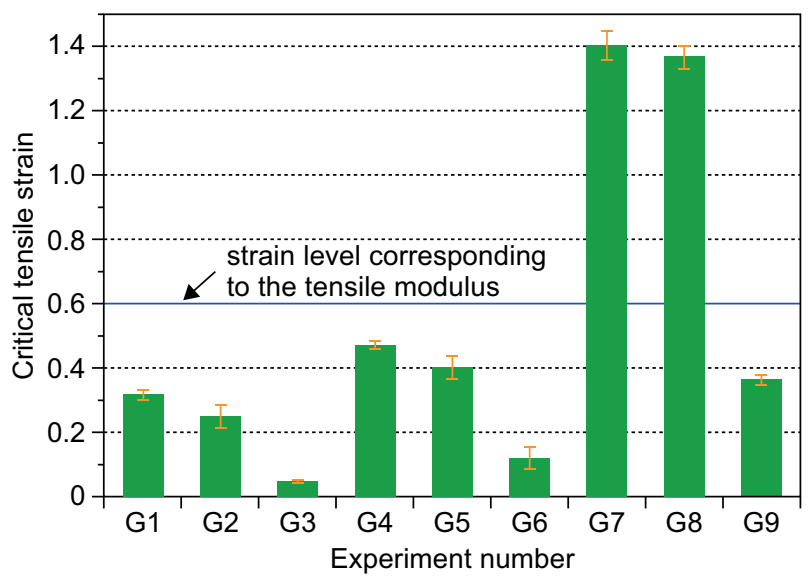

Figure 6. The test results of the critical tensile strain.

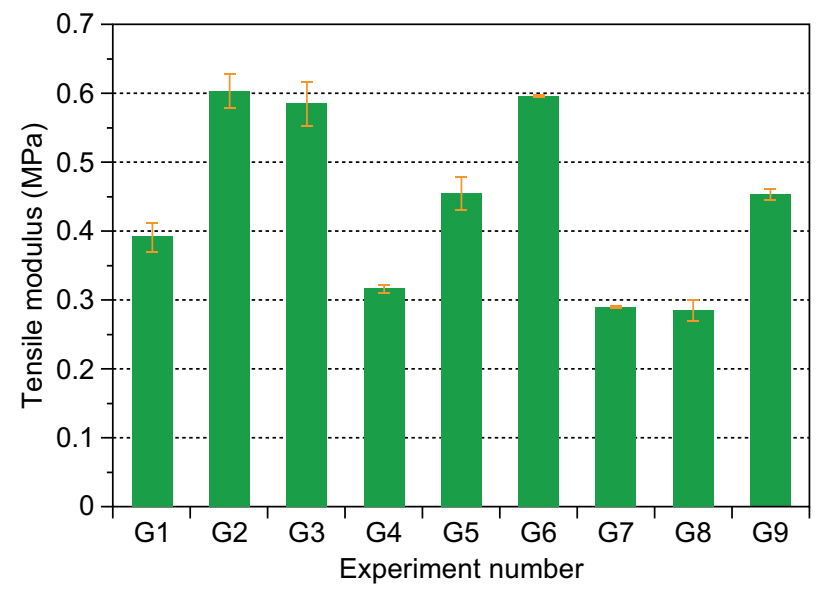

Figure 7. The test results of the tensile modulus.
Analysis of the tensile modulus

The tensile modulus of the specimen is defined as the stress level at which the extension of the specimen reaches $60 \%$ of its original width. The test data of the tensile modulus are presented in Figure 7. The corresponding ANORA and ANOVA results are listed in Table 8. It can be seen that the influences of the three factors on the tensile modulus, as well as their influential orders, are similar to those on the tensile strength. It is noteworthy that only the tensile modulus points for group G7 and G8 locate in the ascending branch of the stress-strain curve, since their critical tensile strain are larger than the strain level corresponding to the tensile modulus (as shown in Figure 6).

\section{Analysis of the elongation at the break}

The elongation at the break $\left(R_{\mathrm{b}}\right)$ can be calculated by Equation 5, where $W_{b}$ is the specimen width at the break point. Following the test data and the analysis results presented in Figure 8 and Table 9, it can be seen that the influences of the three factors on the elongation at the break, as well as their influential orders, are similar

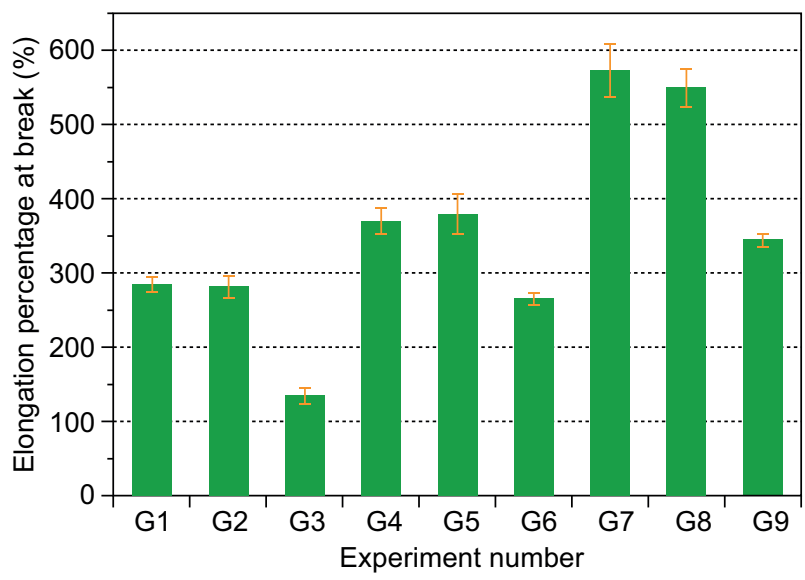

Figure 8 . The test results of the elongation at the break.

Table 7. The ANORA and ANOVA results of the critical tensile strain.

\begin{tabular}{|c|c|c|c|c|c|c|c|c|c|c|}
\hline \multirow{2}{*}{ Influence factor } & \multicolumn{5}{|c|}{ ANORA } & \multicolumn{5}{|c|}{ ANOVA } \\
\hline & $k_{1}$ & $k_{2}$ & $k_{3}$ & $R$ & $S^{2}$ & $F$ & $F$ value & $F_{0.01}$ & $\rho$ & Significance \\
\hline Powder-emulsion ratio & 0.205 & 0.331 & 1.044 & 0.839 & 3.683 & 2 & 92.87 & 5.85 & $59.6 \%$ & $*$ \\
\hline Cement ratio & 0.730 & 0.673 & 0.177 & 0.552 & 1.662 & 2 & 41.91 & 5.85 & $26.5 \%$ & $*$ \\
\hline Filler type & 0.361 & 0.591 & 0.628 & 0.267 & 0.375 & 2 & 9.46 & 5.85 & $5.5 \%$ & $*$ \\
\hline Error & 1 & / & I & / & 0.397 & 20 & / & 5.85 & $8.4 \%$ & l \\
\hline
\end{tabular}

Table 8. The ANORA and ANOVA results of the tensile modulus.

\begin{tabular}{|c|c|c|c|c|c|c|c|c|c|c|}
\hline \multirow{2}{*}{ Influence factor } & \multicolumn{5}{|c|}{ ANORA } & \multicolumn{5}{|c|}{ ANOVA } \\
\hline & $k_{1}$ & $k_{2}$ & $k_{3}$ & $R$ & $S^{2}$ & $f$ & $F$ value & $F_{0.01}$ & $\rho$ & Significance \\
\hline Powder-emulsion ratio & 0.527 & 0.456 & 0.343 & 0.184 & 0.154 & 2 & 97.77 & 5.85 & $36.3 \%$ & $*$ \\
\hline Cement ratio & 0.333 & 0.448 & 0.545 & 0.212 & 0.203 & 2 & 128.99 & 5.85 & $48.1 \%$ & $*$ \\
\hline Filler type & 0.424 & 0.497 & 0.396 & 0.101 & 0.047 & 2 & 29.62 & 5.85 & $10.7 \%$ & $*$ \\
\hline Error & / & / & l & / & 0.016 & 20 & l & 5.85 & $4.9 \%$ & / \\
\hline
\end{tabular}


Bai E-L., Liu G-J., Xu J-Y., Yang N., Wen Ch-H.

Table 9. The ANORA and ANOVA results of the elongation at the break.

\begin{tabular}{|c|c|c|c|c|c|c|c|c|c|c|}
\hline \multirow{2}{*}{ Influence factor } & \multicolumn{5}{|c|}{ ANORA } & \multicolumn{5}{|c|}{ ANOVA } \\
\hline & $k_{1}$ & $k_{2}$ & $k_{3}$ & $R$ & $S^{2}$ & $f$ & $F$ value & $F_{0.01}$ & $\rho$ & Significance \\
\hline Powder-emulsion ratio & 233.7 & 338.0 & 489.4 & 255.7 & 297478.73 & 2 & 150.37 & 5.85 & $62.3 \%$ & $*$ \\
\hline Cement ratio & 409.4 & 403.5 & 248.2 & 161.2 & 150475.75 & 2 & 76.06 & 5.85 & $31.3 \%$ & $*$ \\
\hline Filler type & 336.1 & 373.3 & 351.7 & 37.2 & 6273.40 & 2 & 3.17 & 5.85 & $0.9 \%$ & l \\
\hline Error & l & / & l & l & 19782.71 & 20 & I & 5.85 & $5.4 \%$ & l \\
\hline
\end{tabular}

to those on the critical tensile strain. The effect of the filler type is not significant. The corresponding $F$ value is less than the $F$ standard value.

$$
R_{b}=\frac{W_{b}-W_{0}}{W_{0}} \times 100 \%
$$

\section{DISCUSSION}

From the analyses above, it can be found that the powder-emulsion ratio and the cement ratio are major factors which affect the tensile properties of the FPCC materials. With the increase in the powder-emulsion ratio and the cement ratio, the tensile strength and the tensile modulus increase and the elastic recovery ratio, the critical tensile strain and the elongation at the break decrease. This phenomenon can be explained as follows: Under tensile loading, the mechanical behaviours of the FPCC mainly result from the movement and deformation of the polymer molecular chains. According to the free volume theory, the free volume inside the FPCC is necessary for the polymer molecular chains to change their conformations by movement and rotation. With an increase in the inorganic components, the free volume decreases which hinders the movement of the polymer molecular chains. Thus, the flexibility of the FPCC drops. In addition, the influence of the cement ratio on the tensile strength and the tensile modulus are larger than the influence of the powder-emulsion ratio. However, for the elastic recovery ratio, the critical tensile strain and the elongation at the break, the trend is reversed. This phenomenon indicates that the deformation ability of the FPCC mainly depends on the polymer components. Inorganic components, especially the cement hydration products, are closely related with the strength performances.

The influence of the filler type on the FPCC is far less than the other two factors, since the fillers in the FPCC only play a role in the filling. Within the influences caused by the filler type, adding it with ground calcium carbonate can improve the strength performance and adding it with quartz powder is good for the deformation ability. This phenomenon is probably related with the fineness and the crystal structure of the fillers. The specific reasons need to be further studied. Besides, according to the $F$-test results in the ANOVA, the effects of the filler type on many indicators are significant $\left(F_{i}>F_{0.01}\right)$ while the contribution ratio is much lower. This phenomenon is due to the fact that the indicator variation caused by the test error is less, which makes the $F$-test results more sensitive. Consequently, it is better to use the contribution ratio to make up the deficiencies of the $F$-test.

Lastly, the purpose of the orthogonal experiment is to choose the optimal level for each considered factor. In the view that the strength performance and the deformation ability are two conflicting needs for the FPCC, the level value mainly depends on the requirements of the application. If the FPCC material is required to have not only a better deformation ability, but also a certain strength performance, the powder-emulsion ratio and the cement ratio can be 0.45 and $35 \%$, respectively. In a word, the results and the variation laws obtained in this paper aim to provide the basis of the formulation design of the FPCC material.

\section{CONCLUSIONS}

In this paper, the FPCC material containing the VAE emulsion and Portland cement was prepared. The tensile properties of the FPCC, including the elastic recovery ratio, the tensile strength, the critical tensile strain, the tensile modulus and the elongation at the break, were studied. The influences of the powder-emulsion ratio, the cement ratio and the filler type were investigated by an orthogonal experiment design.

According to the test data and the analysis results, it can be seen that the major influence factors for the tensile properties of the FPCC are the powder-emulsion ratio and the cement ratio. With the increase in these two parameters, the tensile strength and the tensile modulus increase and the elastic recovery ratio, the critical tensile strain and the elongation at the break decrease. Furthermore, for the tensile strength and the tensile modulus, the influence of the cement ratio is more significant than the powder-emulsion ratio, and this is reversed for the case of the elastic recovery ratio, the critical tensile strain and the elongation at the break.

The effect of the filler type on the FPCC is far less than the other two factors although its $F$ test results are significant. The FPCC added with a ground calcium carbonate exhibits a relatively higher tensile strength and tensile modulus. The FPCC added with a quartz powder has a better deformation ability. 


\section{Acknowledgements}

The authors would like to thank the National Natural Science Foundation of China (under Grant No. 51378497) for the financial support.

\section{REFERENCES}

1. Ohama Y.(1997): Recent progress in concrete-polymer composites. Advanced Cement Based Materials, 5(2), 31-40. doi: 10.1016/S1065-7355(96)00005-3

2. Ohama Y. (1998): Polymer-based admixtures. Cement Concrete Composites, 20(2), 189-212. doi: 10.1016/S0958-9465 (97)00065-6

3. Mirza J., Mirza M. S., Lapointe R. (2002): Laboratory and field performance of polymer-modified cement-based repair mortars in cold climates. Construction Building Materials, 16(6), 365-374. doi: 10.1016/S0950-0618(02)00027-2

4. Ma H., Li Z. (2013): Microstructures and mechanical properties of polymer modified mortars under distinct mechanisms. Construction Building Materials, 47(10), 579-587. doi: 10.1016/j.conbuildmat.2013.05.048

5. Zhong S., Chen Z. (2002): Properties of latex blends and its modified cement mortars. Cement and Concrete Research, 32(10), 1515-1524. doi: 10.1016/S0008-8846(02)00813-X

6. Pascal S., Alliche A., Pilvin P. (2004): Mechanical behaviour of polymer modified mortars. Materials Science and Engineering: A, 380(1-2), 1-8. doi: 10.1016/j.msea. 2004.03.049

7. Geetha A., Perumal P. (2012): Effect of waterproofing admixtures on the flexural strength and corrosion resistance of concrete. Journal of the Institution of Engineers (India): Series A, 93(1), 73-78. doi: 10.1007/s40030-012-0009-4

8. Ukrainczyk N., Rogina A. (2013): Styrene-butadiene latex modified calcium aluminate cement mortar. Cement and Concrete Composites, 41(8), 16-23. doi: 10.1016/j. cemconcomp.2013.04.012

9. Ru W., Liang Z. (2015): Mechanism and Durability of Repair Systems in Polymer-Modified Cement Mortars. Advances in Materials Science and Engineering, 2015, 1-8. doi: $10.1155 / 2015 / 594672$

10. Al-Zahrani M. M., Maslehuddin M., Al-Dulaijan S. U., Ibrahim M. (2003): Mechanical properties and durability characteristics of polymer- and cement-based repair materials. Cement and Concrete Composites, 25(4), 527-537. doi: 10.1016/S0958-9465(02)00092-6

11. Almeida A. E. F. D. S., Sichieri E. P. (2007): Experimental study on polymer-modified mortars with silica fume applied to fix porcelain tile. Building and Environment, 42(7), 2645-2650. doi: 10.1016/j.buildenv.2006.07.002

12. Maranhão F. L., John V. M. (2009): Bond strength and transversal deformation aging on cement-polymer adhesive mortar. Construction and Building Materials, 23(2), 10221027. doi: 10.1016/j.conbuildmat.2008.05.019
13. Knapen E., Van Gemert D. (2015): Polymer film formation in cement mortars modified with water-soluble polymers. Cement and Concrete Composites, 58, 23-28. doi: 10.1016/ j.cemconcomp.2014.11.015

14. Wang M., Wang R., Yao H., et al. (2016): Research on the mechanism of polymer latex modified cement. Construction and Building Materials, 111, 710-718. doi: 10.1016/j. conbuildmat.2016.02.117

15. Zhao G. R., Wang P. M., Zhang G. F. (2015): Effect of Latex Film Distributions on Flexibility of Redispersible Polymer Powders Modified Cement Mortar Evaluated by SEM. Advances Materials Research, 1129, 331-338. doi: 10.4028/www.scientific.net/AMR.1129.331

16. Do J., Soh Y. (2003): Performance of polymer-modified self-leveling mortars with high polymer-cement ratio for floor finishing. Cement and Concrete Research, 33(10), 1497-1505. doi: 10.1016/S0008-8846(02)01057-8

17. Tsukagoshi M., Kokami Y., Tanaka K. (2010): Influence of curing condition on film formation of polymer-cement waterproofing membrane. Journal of Structural and Construction Engineering (Transactions of AIJ), 75(652), 1057-1064. doi: 10.3130/aijs.75.1057

18. Diamanti M. V., Brenna A., Bolzoni F., Berra M., Pastore T., Ormellese M. (2013): Effect of polymer modified cementitious coatings on water and chloride permeability in concrete. Construction and Building Materials, 49(6), 720-728. doi: 10.1016/j.conbuildmat.2013.08.050

19. Xue X., Yang J., Zhang W., Jiang L., Qu J., Xu L., Zhang H., Song J., Zhang R., Li Y., Qin J., Zhang Z. (2015): The study of an energy efficient cool white roof coating based on styrene acrylate copolymer and cement for waterproofing purpose - Part II: Mechanical and water impermeability properties. Construction and Building Materials, 96, 666-672. doi: 10.1016/j.conbuildmat.2015.08.033

20. Assaad, Jean J. (2018): Development and use of polymermodified cement for adhesive and repair applications. Construction and Building Materials, 163, 139-148. doi: 10.1016/j.conbuildmat.2017.12.103

21. Rashid K., Ueda T., Zhang D., Miyaguchi K., Nakai H. (2015): Experimental and analytical investigations on the behavior of interface between concrete and polymer cement mortar under hygrothermal conditions. Construction and Building Materials, 94, 414-425. doi: 10.1016/j. conbuildmat.2015.07.035

22. Chinese Standard. (2009). Common portland cement. GB 175-2007/XG1-2009. Ministry of Construction of the People's Republic of China and Quality Supervision Inspection and Quarantine of the People's Republic of China, (in Chinese).

23. Chinese Standard. (2002). Test method for building sealants. GB/T 13477-2002. Quality Supervision Inspection and Quarantine of the People's Republic of China, (in Chinese).

24. Zhang X., Kuang C., Fang Z., Liu X., Wang G., Lai S. (2014): Orthogonal experimental study on strength of steel fiber reinforced fly ash recycled concrete. Journal of Building Materials, 17(4), 677-684 (in Chinese). doi: 10.3969/ j.issn.1007-9629.2014.04.021 